\title{
INITIAL RESULTS WITH LOW ENERGY SINGLE STAGE AMS
}

\author{
J B Schroeder • T M Hauser • G M Klody • G A Norton \\ National Electrostatics Corporation, Middleton, Wisconsin, USA. Email: nec@pelletron.com.
}

ABSTRACT. The National Electrostatics Corporation has built and tested a prototype low energy, open-air, single stage carbon accelerator mass spectrometry (AMS) system (patent pending). The configuration tested has a standard 40-sample, multicathode SNICS source on a 300-kV deck. The beam is mass analyzed before acceleration to a gas stripper located at ground. The ${ }^{14} \mathrm{C}^{+}$ions are separated from ${ }^{13} \mathrm{C}^{+}$and ${ }^{12} \mathrm{C}^{+}$arising from the molecular breakup by a $90^{\circ}$ analyzing magnet immediately after the gas stripper which acts as a molecular dissociator. The ${ }^{14} \mathrm{C}^{+}$beam passes through an electrostatic spherical analyzer before entering the particle detector. The observed ${ }^{14} \mathrm{C} /{ }^{12} \mathrm{C}$ precision is better than $5 \%$ with a sensitivity of better than $0.05 \mathrm{dpm} / \mathrm{gmC}$. A first single stage AMS system has been ordered. The configuration of this system will be discussed.

\section{INTRODUCTION}

The vast majority of accelerator mass spectrometry (AMS) systems are based on dual stage (tandem), high pressure gas-insulated, high voltage, electrostatic accelerators. Briefly, in existing AMS instruments, the sample to be measured is placed in a negative ion source relatively close to ground potential. In the ion source, some of the atoms/molecules of the sample are negatively ionized, filtered, and injected into a tandem accelerator, where they are accelerated to the positively-charged high voltage terminal. There they enter a "stripper" (commonly, a long, narrow tube filled with rarified gas) where 2 or more electrons are removed (stripped) so they become positively charged. Then, they are accelerated back to ground potential and are analyzed and measured. A secondary but highly advantageous feature of the stripper is that interfering molecular ions are dissociated by collisions with the stripper gas and, hence, are prevented from introducing errors in the isotopic ratio measurements.

Until recent years, all of these systems have terminal potentials in the multimillion volt range and utilize charge states $3+$ or $4+$. Though the level of performance of these machines is high, they have the disadvantage of being relatively large and expensive. The group, under the direction of Martin Suter at ETH Hönggerberg, has shown that a small, $0.5 \mathrm{MV}$ tandem accelerator, using the 1+ charge state for carbon, provides high-precision measurements similar to the multimillion volt systems (Suter et al. 1999; Synal et al. 2000). In addition to the system built at ETH, 3 similar commercial systems are in use and a fourth system is in manufacture. During factory tests, all the systems presently in use routinely demonstrated precisions between $3 \%$ and $5 \%$ for carbon.

Experiments with these low voltage tandems indicated that complete molecular destruction can be achieved at energies as low as $250 \mathrm{keV}$. This suggested that a relatively low voltage, open-air insulated accelerator could be a practical alternative to a high pressure gas-insulated tandem. Furthermore, molecular destruction occurs after the first acceleration stage, rendering the second stage acceleration superfluous for the purposes of AMS. Indeed, this second stage has the disadvantage of allowing for charge exchange of molecular fragments, yielding ions with momentum equal to the rare isotope.

Based on these considerations, the National Electrostatics Corporation developed a new device, the Single Stage Accelerator Mass Spectrometer (SSAMS).

\section{EXPERIMENTAL}

A prototype system was built and tested over a 1-yr period. A 300-kV deck was constructed (Figure 1) with a standard 40 sample multi-cathode source of negative ions by cesium sputtering (40 MCSNICS), followed by a $90^{\circ}$ mass analysis magnet. The injection energy was about $40 \mathrm{keV}$.

(C) 2004 by the Arizona Board of Regents on behalf of the University of Arizona

Proceedings of the 18th International Radiocarbon Conference, edited by N Beavan Athfield and R J Sparks

RADIOCARBON, Vol 46, Nr 1, 2004, p 1-4 


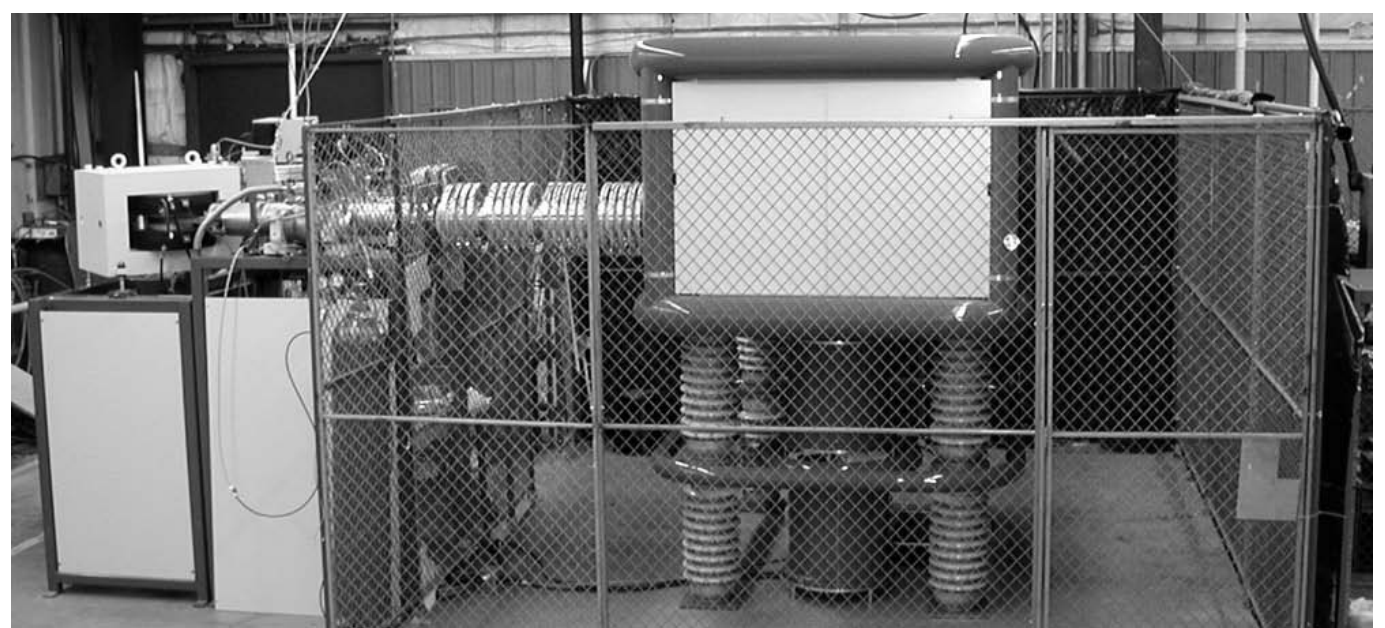

Figure 1 Prototype Single Stage AMS system with the acceleration tube exiting the $300 \mathrm{kV}$ deck to the left, followed by the gas stripper and $90^{\circ}$ energy analysis magnet.

In sequence, the gas stripper (molecular dissociator), energy analysis magnet, and electrostatic spherical analyzer are all located at ground potential, followed by the silicon surface barrier detector. This system allows for the transmission of the mass 14 beam only. The current of the mass 12 negative ion beam is measured in an offset suppressed Faraday cup immediately after the $90^{\circ}$ analyzing magnet on the $300 \mathrm{kV}$ deck. Figure 2 shows the system configuration.

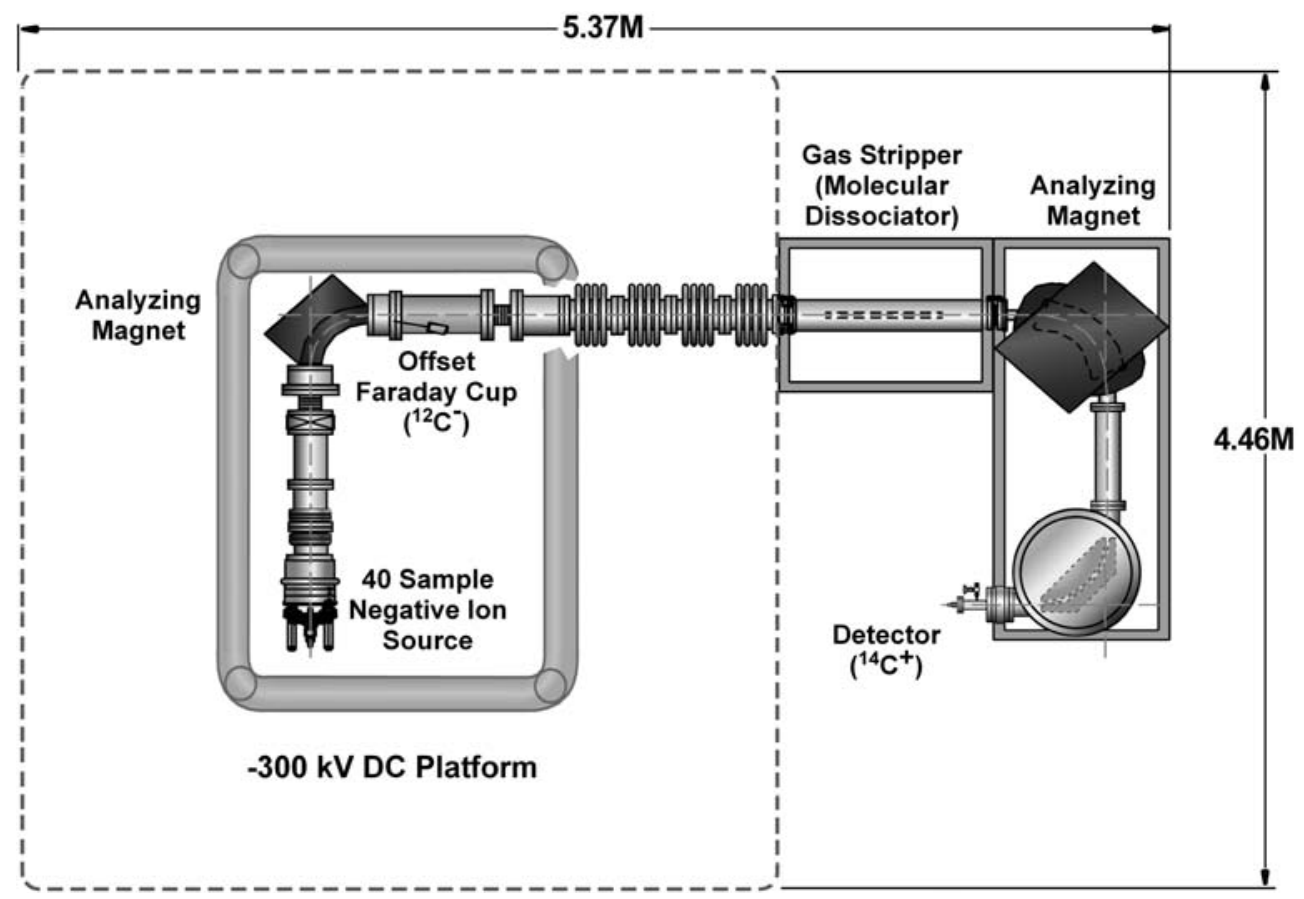

Figure 2 The prototype Single Stage AMS system has the 40 sample negative carbon source followed by a $90^{\circ}$ permanent magnet for mass analysis. The mass 12 beam was measured before acceleration. The gas stripper, $90^{\circ}$ analyzing magnet, $90^{\circ}$ electrostatic spherical analyzer, and detector are located at ground potential. 
The system is equipped with four $250 \mathrm{~L} / \mathrm{sec}$ turbo molecular pumps. The first is located immediately after the ion source before the first $90^{\circ}$ magnet. Two of the turbo pumps are located on the differentially-pumped gas stripper housing. It provides a stripper thickness of about $2 \mu \mathrm{g} / \mathrm{cm}^{2}$ using either nitrogen or argon. The 4th turbo molecular pump is located on the housing of the $90^{\circ}$ electrostatic spherical deflector. During AMS measurements, the vacuum maintained along the beamline, outside of the gas stripper, was between $10^{-6}$ to $10^{-7}$ Torr.

Experiments were conducted using graphite from Poco, ANU sucrose, OXII, beer, and Alfa Aesar for background measurements. The beam currents ranged from $80 \mu \mathrm{A}$ to $100 \mu \mathrm{A}$, of which about $50 \%$ was C-. The deck potential was varied from $250 \mathrm{kV}$ to $300 \mathrm{kV}$ for a ${ }^{14} \mathrm{C}^{+}$beam energy at the detector of $290 \mathrm{keV}$ to $340 \mathrm{keV}$.

\section{RESULTS}

Unlike all other high-precision accelerator-based AMS systems, the mass 12 and mass 13 beams were only measured at the low energy Faraday cup. Therefore, it was necessary to do an experiment to determine the actual particle transmission from the source to the detector. The system configuration would allow the transmission of the mass 13 beam through the stripper to the detector by varying the injection parameters to measure the mass 13 beam at the low energy offset cup. From this measurement, it was determined that the particle transmission was $52 \%$ at a deck bias of $300 \mathrm{kV}$, which is consistent with the expected stripping yield for carbon (Synal et al. 2000).

Background, precision, and efficiency measurements were done from a deck potential of $250 \mathrm{kV}$ to $300 \mathrm{kV}$. There was no significant variation in this range. For background measurements, graphite from Alfa Aesar was used. Backgrounds from 48,000 BP (based on $724{ }^{14} \mathrm{C}$ events) to 51,000 BP were seen.

Measurements of precision were done using graphite made from beer $\mathrm{CO}_{2}$. Measurements taken over 3 cathodes positioned in 3 different quadrants of the standard 40-sample MC-SNICS cathode disk yielded a routine precision of $5 \%$ for $259,330{ }^{14} \mathrm{C}$ events. The best precision seen was $3 \%$.

The increased scattering expected at these low beam energies is cause for concern related to ${ }^{14} \mathrm{C}$ transmission through the stripper tube. The ${ }^{14} \mathrm{C}$ events given above required a charge collection of 0.103 Coulombs on the low energy mass 12 cup. This corresponds to $69 \%$ of the typical efficiency of a $3 \mathrm{MV}$ tandem AMS system. Table 1 compares the efficiencies of $3.0 \mathrm{MV}$ tandem, $0.5 \mathrm{MV}$ tandem, and 0.3 MV single stage AMS systems.

Table 1 Beam efficiency comparison.

\begin{tabular}{llllll}
\hline AMS system & $\begin{array}{l}\text { Beam energy } \\
\text { at stripper }\end{array}$ & Sample & $\begin{array}{l}{ }^{12} \mathrm{C} \text { charge } \\
\text { collected }\end{array}$ & $\begin{array}{l}{ }^{14} \mathrm{C} \text { events } \\
\text { (scattering loss) }\end{array}$ \\
\hline IAA $^{\mathrm{b}}$ & $2.66 \mathrm{MeV}$ & ANU & 0.0637 Coulombs & 627,061 & 1.00 \\
Poznań $^{\mathrm{c}}$ & $0.51 \mathrm{MeV}$ & OXII & 0.0487 Coulombs & 404,403 & 0.95 \\
Single stage & $0.33 \mathrm{MeV}$ & Beer $^{\mathrm{d}}$ & 0.1030 Coulombs $^{\mathrm{e}}$ & 259,331 & 0.69 \\
\hline
\end{tabular}

${ }^{a}$ Efficiency reduced because of scattering loss in the stripper relative to the IAA system after normalization to fraction modern.

${ }^{b}$ Institute of Accelerator Analysis, Japan, factory test.

'Poznań Radiocarbon Laboratory, Poland, factory test.

${ }^{\mathrm{d}}$ Used 1.08 fraction modern.

${ }^{\mathrm{e}}$ Measured at low energy Faraday cup; used 0.52 particle transmission. 


\section{CONCLUSION}

The prototype design was targeted at users with modest precision requirements $(5 \%)$ and that goal was successfully demonstrated. However, the results of this experiment clearly indicate that a more complex design with simultaneous or sequential injection will provide the same or better background, precision, and efficiency. Accelerating only the mass 14 beam through the system does not provide the same level of confidence as sequential or simultaneous injection where mass 13 and 12 beams are measured after molecular disassociation and high-energy analysis.

The first commercial version of the system will have sequential injection and is presently in manufacture. The system is being built for the Radiocarbon Laboratory at the Geobiosphere Science Center in Lund, Sweden. In this configuration (Figure 3), the dual ion source injector is located near ground potential, with the gas stripper and the high energy analysis system with detector located on the $250 \mathrm{kV}$ deck. Beam testing is scheduled to begin in Spring 2004.

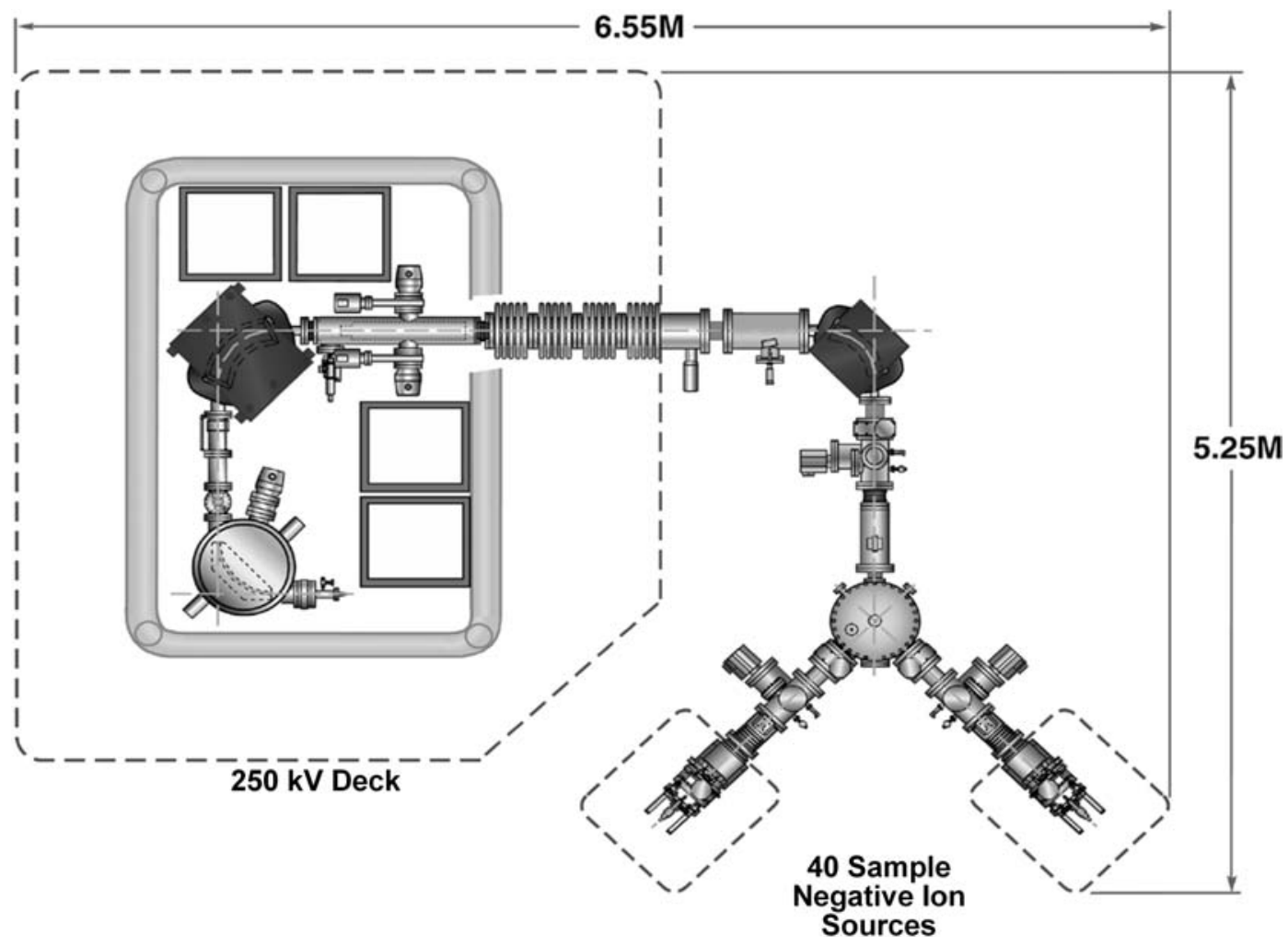

Figure 3 The first commercial Single Stage AMS system is equipped with a sequential, dual ion source injector, allowing mass 12 and 13 to be measured after the final $90^{\circ}$ analyzing magnet on the high-voltage deck. This configuration is the reverse of the prototype with the injector system at ground potential to allow greater sample handling flexibility.

\section{REFERENCES}

Suter M, Huber R, Jacob SAW, Synal H-A, Schroeder JB. 1999. A new small accelerator for radiocarbon dating. 15th International Conference on Application of Accelerators in Research and Industry. 4-7 November
1998. Denton, Texas. American Institute of Physics. Synal H-A, Jacob S, Suter M. 2000. New concepts for radiocarbon detection systems. Nuclear Instruments and Methods in Physics Research B 161-163:29-36. 